\title{
Neglected Orodental Facts during General Anesthesia and Intensive Care Unit Admission in Pediatric Population
}

\author{
Karim Poorsattar Bejeh Mir ${ }^{1}$, Arash Poorsattar Bejeh Mir ${ }^{2}$
}

Summary: Poorsattar Bejeh Mir K, Poorsattar Bejeh Mir A - Neglected Orodental Facts during General Anesthesia and Intensive Care Unit Admission in Pediatric Population.

Keywords: Anesthesiology; Dentistry; Education, Professional; Intensive Care Units; Pneumonia, Ventilator-Associated; Wounds and Injuries.

\section{COMMENTARY}

Perianesthetic dental trauma is not uncommon with an incidence as low as $0.02 \%-0.07 \%$ up to $12.1 \%$ of cases of the general anesthesia (GA) ${ }^{1}$. Incidence of overall oral trauma is reported as high as $7 \%$ of individuals who underwent GA ${ }^{2}$. Indeed, emergency endotracheal intubation and less experienced staff probably increase the chance of traumatizing hard and soft oral tissues ${ }^{3}$. The majority of incidental dental traumas during GA occur in attempting intubation (75\%), followed by extubation $(16 \%)$ and in the recovery phase $(9 \%)^{4}$.

Dental trauma includes milder forms - such as enamel fracture or tooth subluxation - to more severe forms of crown fractures and tooth avulsion. Anterior dislocation of mandible condyle leading to a locked position of temporomandibular joint, tongue injuries and a variety forms of pressure-induced lesions of the oral cavity soft tissues are also explained ${ }^{1,5}$.

During life, dentition includes three phases: deciduous (6 months - 6 years), mixed ( $6-12$ years) and permanent dentition (beyond 12 years) ${ }^{6}$. Upper incisors are reported to be more affected during intubation ${ }^{4}$. These teeth are single-rooted with a low surface area when compared to multiple-rooted posterior teeth with a significant higher surface area around the roots within the alveolar bone. The higher traumatic injuries may be explained by unintentional forces directed to the tooth when an anesthesiologist uses this tooth as a fulcrum to guide the laryngoscope blade especially during the difficult and previously failed attempts ${ }^{4}$.

Received from Dentistry Student Research Committee (DSRC), Babol University of Medical Sciences, Ganj Afrooz Ave, Babol, Mazandaran Province, Iran.

1. Mir; MD; Private practice, Head, Pediatrics Department, Amir Mazandarani General Hospital, Sari, Iran

2. Mir; Undergraduate Dentistry Student, Dentistry Student Research Committee (DSRC), Dental Materials Research Center, Babol University of Medical Sciences, Babol, Iran

Submitted on October 28, 2011.

Approved on November 9, 2011

Correspondence to:

Arash Poorsattar Bejeh Mir,

Dentistry Student Research Committee (DSRC),

Babol University of Medical Sciences, Ganj Afrooz Ave,

Babol, Mazandaran Province, Iran

E-mail: arashpoorsattar@yahoo.com
As the child finishes the deciduous dentition and enters the transitional phase of mixed dentition at around the age of 6-8 years, the underlying permanent incisor would exert its eruptive forces by loosening the corresponding deciduous ${ }^{6}$. This may challenge both the child and intensivist by a high probability of deciduous dentition to be avulsed with subsequent chance of permanent teeth damage by excessive forces and wrong attempt to re-implant the avulsed tooth. Another special consideration for toddlers is the presence of "baby bottle syndrome" or early childhood caries (ECC) ${ }^{1}$. This syndrome is derived from long exposure to the high sugar content liquids especially at night during the age of 18-48 months. Upper incisors and lower molars are affected most, yet lower incisors are spared due to the tongue's protective function ${ }^{1}$. These teeth with rampant and extensive caries are more susceptible to mechanical trauma and more likely to crack or avulse ${ }^{1}$.

Pediatric intensive care unit (PICU) admitted patients who are remarkably at risk for dental trauma when compared to adults for their immature root formation and possibility of physiologic subluxed teeth during their dentition phase ${ }^{7}$. One should keep in mind having adequate knowledge about additive hazards when the physician attempts to intubate a pediatric patient with class II malocclusion (i.e., protrusion of maxilla) and excessive overjet ${ }^{7}$ or abnormally large and over extruded front teeth, so called "Bugs Bunny teeth". In addition to forceful intubation or extubation, vigorous suctioning of posterior teeth, pressure induced damage to the adjacent tissues by insertion of the laryngeal mask airway (LMA), masseteric spasm derived by hypothermic-induced shivering and biting forces against antagonist teeth or endotracheal tube (ETT) should all be taken into account. Hence, intubation, extubation and suctioning should be performed with a great care. If the child has a loose tooth and avulsion or aspiration is deemed, a careful suturing (3-0 silk suture) of the affected tooth to the adjacent sound tooth just around the crown of the teeth may prevent avulsion and aspiration ${ }^{1}$.

It is clear that attenuated mechanical elimination and poor oral hygiene in intensive care units increase the dental plaques. Dental plaque consists of more than 300 microorganism species which are embedded into an extracellular matrix 6,8 . 
Dental plaque, if remained unmet, can induce gingivitis in less than ten days with subsequent progression to periodontitis as a more severe and profound state of the disease. Moreover, within first 48 hours of admission in the intensive care units oral flora changes from aerobic gram positive bacteria to more perio-pathogenic anaerobic gram negative rods ${ }^{6}$. Elevated dental plaque may increase the risk of ventilator associated pneumonia (VAP). VAP occurs at the rate of 11.6 per 1000-day of mechanical ventilation in PICUs of the United States ${ }^{6,8}$. A controversial body of literature exists regarding the effect of the oral hygiene on VAP incidence by either pharmacologic or non pharmacologic intervention ${ }^{8}$. A recent systematic review and meta-analysis showed Chlorhexidine mouth wash can reduce VAP (recommendation grade B) and tooth brushes, tooth paste and cotton swabs may reduce VAP to a lesser extent (recommendation grade D) ${ }^{5}$. Other pharmacologic interventions such as sodium bicarbonate, normal saline and essential oil Listerine (phenol based mouthwash) are still unresolved issues and cannot be recommended for routine administration. Furthermore, passage of NG tubes and endotracheal tubes unavoidably keep mouth open and xerostomia may happen. Common medications such as diuretics, anticholinergics, anticonvulsants and possible dehydration can aggravate xerostomia and mucositis ${ }^{6}$.

Currently, the American Association of Critical-Care Nurses (AACN) recommends checking the oral cavity every 8 hours. This assessment may include attention to BRUSED Teeth; $\mathrm{B}$ : bleeding, R: redness, U: ulceration, S: saliva, $\mathrm{H}$ : halitosis, $\mathrm{E}$ : external factors including taps and tubes and D: debris ${ }^{9}$. Routinely, prophylaxis for peptic ulcer is prescribed in PICUs. Nevertheless, the heavy emotional and systemic stresses on periodontal health are simply overlooked. Stress is shown to adversely affect periodontal health ${ }^{10}$. Also, a bidirectional relationship between periodontitis and systemic illnesses is elucidated. Periodontitis may induce vasculopathy by direct invasion of bacteria to the endothelium or promote cascades of inflammatory cytokine such as IL-1 and TNF $\alpha^{11}$. This cascade may aggravate existing free radical related illnesses and may elevate nitric oxide level with probable hypotensive consequences of septic shock ${ }^{11,12}$.

For the management of unintentional dental trauma, clinicians should be aware that avulsed deciduous tooth should not be implanted in its socket, because of the possible damage to the underlying permanent bud or erupting tooth. If a permanent tooth is avulsed, the tooth should be kept at the crown (root should not be touched to reduce the most crucial prognostic cells of periodontal ligament) and be re-implanted within 30 minutes, if possible. The best available medium to keep the avulsed tooth is fresh cold milk or normal saline while emergent consultation is requested. Avulsed teeth should not be washed with disinfectant solutions ${ }^{13-15}$. If many hours have gone by since the avulsion or the avulsed tooth is not found, parents should be aware of the problem. The space should be preserved by a space maintainer to prevent being occupied by titling adjacent teeth, maintaining the space for future, more definite treatment performed at age of eighteen ${ }^{16}$.

In conclusion, it seems that many aspects of oral health are neglected by merely giving attention to lifesaving procedures, neglecting organ-saving practices. More comprehensive and problem-oriented teaching courses for subspecialty fellows or nurses involved in critically ill pediatric patient care may warrant more professional insight into the different stages of dentitions, endotracheal intubation complications concerning hard and soft oral tissue damages ${ }^{17}$ and management options for when traumatic injury happens. We recommend a speciality dental visit in the case of severe illnesses or prolonging the hospital stay in PICU or after discharge. Future prospective large-scale investigations of periodontal health of PICU admitted children would help clarify this concern more precisely. 


\section{REFERENCES}

1. Yasny JS - Perioperative dental considerations for the anesthesiologist. Anesth Analg, 2009;108:1564-1573.

2. Fung BK, Chan MY - Incidence of oral tissue trauma after the administration of general anesthesia. Acta Anaesthesiol Sin, 2001;39:163167.

3. Martin LD, Mhyre JM, Shanks AM, Tremper KK, Kheterpal S - 3,423 emergency tracheal intubations at a university hospital: airway outcomes and complications. Anesthesiology, 2011;114:42-48.

4. Monaca E, Fock N, Doehn M, Wappler F - The effectiveness of preformed tooth protectors during endotracheal intubation: an upper jaw model. Anesth Analg, 2007;105:1326-1332.

5. Berry AM, Davidson PM, Masters J, Rolls K - Systematic literature review of oral hygiene practices for intensive care patients receiving mechanical ventilation. Am J Crit Care, 2007;16:552-562.

6. Johnstone L, Spence D, Koziol-McClain J - Oral hygiene care in the pediatric intensive care unit: practice recommendations. Pediatr Nurs, 2010;36:85-96.

7. Johnson A, Lockie J - Anaesthesia and dental trauma. Anaesth Intensive Care, 2005;6:271-272. 


\section{VARIÁVEIS BUCODENTAIS NEGLIGENCIADAS DURANTE ANESTESIA GERAL E INTERNAÇÃO}

EM UNIDADE DE TERAPIA INTENSIVA DE POPULAÇÃO PEDIÁTRICA

8. Garcia R, Jendresky L, Colbert L, Bailey A, Zaman M, Majumder M - Reducing ventilator-associated pneumonia through advanced oraldental care: a 48-month study. Am J Crit Care, 2009;18:523-532.

9. Abidia RF - Oral care in the intensive care unit: a review. J Contemp Dent Pract, 2007;8:76-82.

10. Rosania AE, Low KG, McCormick CM, Rosania DA - Stress, depression, cortisol, and periodontal disease. J Periodontol, 2009;80:260-266.

11. Cueto A, Mesa F, Bravo M, Ocaña-Riola R - Periodontitis as risk factor for acute myocardial infarction. A case control study of Spanish adults. J Periodontal Res, 2005;40:36-42.

12. Petros A, Bennett $D$, Vallance $P$ - Effect of nitric oxide synthase inhibitors on hypotension in patients with septic shock. Lancet. 1991;338:1557-1558.

13. Flores MT, Andreasen JO, Bakland LK et al. - Guidelines for the evaluation and management of traumatic dental injuries. Dent Traumatol, 2001;17:1-4.

14. Flores MT, Andreasen JO, Bakland LK et al. - Guidelines for the evaluation and management of traumatic dental injuries. Dent Traumatol, 2001;17:49-52
15. Flores MT, Andreasen JO, Bakland LK et al. - Guidelines for the evaluation and management of traumatic dental injuries. Dent Traumatol, 2001;17:97-102.

16. Sowmya B, Raghavendra P - Management of dental trauma to a developing permanent tooth during endotracheal intubation. $J$ Anaesthesiol Clin Pharmacol, 2011;27:266-268.

17. Poorsattar Bejeh Mir K, Poorsattar Bejeh Mir A - Prenatal and perinatal burden on dentoalvelor development: awareness of need for especial dentistry follow up program for premature neonates. Indian J Pediatr, 2011 May 28. [Epub ahead of print] 